\title{
EDUCAÇÃO EM SAÚDE NO PRÉ-NATAL A PARTIR DO REFERENCIAL TEÓRICO DE PAULO FREIRE
}

\author{
PRENATAL HEALTH EDUCATION FROM THE THEORETICAL FRAMEWORK OF PAULO FREIRE \\ EDUCACIÓN EN SALUD EN EL PRENATAL A PARTIR DEL REFERENCIA TEÓRICO DE PAULO FREIRE
}

\author{
Daniely Quintão Fagundes ${ }^{1}$ \\ Adauto Emmerich Oliveira ${ }^{2}$
}

Resumo Neste artigo, discutiu-se o processo de construção de uma proposta de educação em saúde para o pré-natal por gestantes e profissionais de saúde com base no referencial teórico de Paulo Freire. Foi realizado um estudo qualitativo apoiado na metodologia da pesquisa-ação em uma unidade básica de saúde do município de Vitória, capital do estado do Espírito Santo, em 2014. Os dados foram coletados por meio da observação participante, com a gravação em áudio dos encontros. A análise do material ocorreu simultaneamente, e em cada reunião os resultados parciais eram submetidos à avaliação dos participantes, que novamente discutiam e refletiam sobre as conclusões obtidas. Tais avaliações possibilitaram a elaboração de um relatório final do processo com a proposição de ações de transformação da realidade. Os resultados mostraram que profissionais de saúde e gestantes contribuíam diferentemente e complementarmente na escolha de temas para a educação no pré-natal, evidenciando a importância da interação entre servidores e usuários na construção de projetos educativos fundamentados no diálogo. Também foram evidenciados problemas organizacionais e estruturais nos serviços de saúde que dificultavam a realização das atividades, tornando necessárias reflexões-ações que envolvam gestores e administradores do Sistema Único de Saúde, a fim de que a educação se torne uma prioridade.

Palavras-chave educação em saúde; cuidado pré-natal; pesquisa qualitativa.
Abstract This article discusses the process of building a health education proposal for prenatal care for pregnant women and health professionals based on the theoretical framework of Paulo Freire. A qualitative study supported on the research-action methodology was carried out in a basic health unit in the municipality of Vitória, capital of the state of Espírito Santo, Brazil, 2014. Data were collected through participant observation with the audio recording of the meetings. The material was analyzed simultaneously, and at each meeting the partial results were submitted to the evaluation of the participants, who again discussed and reflected on the conclusions reached. Such evaluations enabled the preparation of a final report on the process with the proposition of reality transformation actions. The results showed that pregnant women and health professionals contributed differently and complementarily in the choice of topics for education on prenatal care, highlighting the importance of the interaction between servers and users in the construction of educational projects based on dialogue. Also highlighted were organizational and structural issues in health services that made it difficult to carry out the activities, causing the need for reflections-actions involving Unified Health System managers and administrators, so that education becomes a priority.

Keywords health education; prenatal care; qualitative research. 


\section{Introdução}

A atenção obstétrica e neonatal prestada pelos serviços de saúde deve ter como características essenciais qualidade e humanização. É dever dos serviços e profissionais de saúde acolher com dignidade a mulher e o recém-nascido, enfocando-os como sujeitos de direitos (Brasil, 2005). Entretanto, evidencia-se que apesar dos grandes avanços na saúde materno-infantil desde a implantação do Programa de Assistência Integral à Saúde da Mulher (PAISM), em 1984, e posteriormente do Programa de Humanização no Pré-Natal e Nascimento (PHPN), no ano 2000, e da Rede Cegonha, em 2011, a qualidade da assistência pré-natal tem sido questionada por diversos estudos (Serruya, Ceccati e Lago, 2004; Santos Neto et al., 2012; Martinelli et al., 2014).

Apesar das ações de humanização do pré-natal preconizadas pelo PHPN e do efeito positivo das ações participativas para as mulheres, existe uma contradição na prática da assistência à saúde oferecida à população, com um modelo ainda atrelado à medicina preventiva (Souza, Roecker e Marcon, 2011). Tal tipo de abordagem centra-se no diagnóstico e tratamento de problemas de saúde e não abarca necessariamente toda a complexidade que cada tema exige, restringindo-se apenas ao campo delimitado da doença e/ou da restauração do funcionamento dos órgãos. Essa condição não privilegia uma discussão coletiva entre as próprias mulheres, além de não permitir o desenvolvimento da percepção de outras demandas (Trindade e Ferreira, 2008), que muitas vezes são diferentes das necessidades evidenciadas pelos profissionais de saúde.

Conforme Paim (2008), o distanciamento entre as reais necessidades das mulheres e aquilo que é oferecido pelos serviços de saúde se deve em grande parte à ausência de diálogo entre profissionais e usuárias, motivada pela constituição do sistema formador tecnicista, e à organização dos serviços de saúde focada na obtenção de metas, em razão da constituição do Sistema Único de Saúde (SUS) sem uma ruptura com a ideologia neoliberal.

O desenvolvimento da saúde materno-infantil alinhado com a ideia da humanização, para ser colocado em prática, necessita de uma recondução pela via da educação problematizadora, em conformidade com o que foi proposto pela recente Política de Educação Popular em Saúde (PNEPS-SUS) (Brasil, 2013). Esta propõe uma prática político-pedagógica que perpassa as ações voltadas para promoção, proteção e recuperação da saúde, mediante o diálogo entre a diversidade de saberes, valorizando os saberes populares, a ancestralidade, o incentivo à produção individual e coletiva de conhecimentos e a inserção destes no SUS.

As necessidades evidenciadas no campo do diálogo, da reflexão e da orientação do SUS aproximam-se da fundamentação de Paulo Freire, teórico que discutiu a educação como forma de politização, conscientização e 
humanização do homem. Freire (1992) destacou que não é possível educar sem uma compreensão de nós mesmos como seres históricos, políticos, sociais e culturais, e isto a educação e o treinamento apenas técnico não proporcionam - o que clarifica a situação atual da educação em saúde, pois a organização do sistema encontra-se fundamentada na visão focalista difundida pelo modelo biomédico. Para Freire (1987), esta abordagem enfatiza a visão unicausal dos problemas, desconsiderando a complexa totalidade. Tais formas de ação, intensificando o modo focalista de existência das massas oprimidas, dificultam sua percepção crítica da realidade e as mantêm ilhadas.

A abordagem dita 'freireana' oferece uma nova forma de condução do processo educativo, que parte de uma investigação inicial do universo dos sujeitos. Por meio dessa investigação, 'palavras geradoras' são identificadas, assim chamadas porque propiciam a percepção de outras que revelam a realidade a ser explorada, desejos, frustrações, desilusões, esperanças e, frequentemente, certos momentos estéticos da linguagem popular (Freire, 2011). Dessa forma, cada palavra - ou conjunto delas - é relacionada a temas que devem ser apresentados de maneira simples, para que ofereça possibilidades plurais de descodificação, e à medida que esse processo ocorre novos temas podem surgir.

É importante destacar que a forma como cada tema é discutido com o grupo nada se assemelha ao método educacional vigente, em que o educador está à frente da classe e proclama um monólogo detentor do saber, enquanto os ditos alunos recebem os conteúdos, chamados por Freire (1987) de depósitos, pois são depositados em suas mentes sem qualquer reflexão acerca dos seus significados. Por isso a proposição 'freireana' propõe a realização de 'círculos de cultura', nos quais educadores e alunos estão em posição de igualdade, e o ato de educar não é feito apenas pelo educador, mas por todos.

Para Oliveira e colaboradores (2014), os círculos de cultura representam uma aposta em que os sujeitos estão engajados no ato de conhecer e transformar a realidade, ao permitir que questões separadas sejam ligadas como facetas de um mesmo objeto. Além disso, os 'conteúdos' não são definidos de maneira verticalizada, mas sim de forma democrática, com base nos problemas identificados na realidade local dos sujeitos participantes.

No que se refere à aplicação dessa proposta para a educação em saúde no pré-natal, Sartori e Van der Sand (2004) ressaltam que esse tipo de educação favorece uma condição indispensável para que os participantes enfrentem as situações de mudanças geradas por certo grau de distorções e medo, uma vez que tende a 're-significar' suas vivências por meio do reconhecimento dos outros e de si. Por isso, de acordo com Rios e Vieira (2007), ações educativas no pré-natal devem, preferencialmente, ser realizadas por meio de metodologias participativas, garantindo assim que o conhecimento prévio das mulheres seja intercambiado dentro dos grupos formados nos serviços de saúde. 
A proposta pedagógica de Paulo Freire é mais do que um simples método engessado sobre como fazer a educação, porque busca o reconhecimento dos homens e mulheres como sujeitos. Dessa maneira, a opção por desenvolver ações educativas fundamentadas em Paulo Freire exige uma reinvenção, que no estudo apresentado neste artigo está alinhada à pesquisa-ação, porque de acordo com Morin (2004) esse tipo de abordagem possibilita revisar decisões de curto e médio prazos e rever sua visão global ou holística, pois como se trata de uma abordagem ligada à condição humana, é necessário espaço para dinamismo no processo.

A escolha por esse tema de pesquisa justificou-se em razão das limitações destacadas no SUS e que são consideradas por Freire (1987) como 'situações-limite', as quais podem ser transcendidas pela conscientização, agente de produção do 'inédito viável' e da mudança por meio da ação consciente. Por isso, o estudo utilizou a proposta de Paulo Freire para construir um projeto de educação em saúde para o pré-natal com gestantes e profissionais de saúde de uma unidade básica de saúde (UBS) da cidade de Vitória, Espírito Santo.

\section{Percurso metodológico para a construção do projeto de educação em saúde para o pré-natal}

O estudo apresentado neste artigo é um recorte da pesquisa de mestrado intitulada Ações de educação em saúde para o pré-natal (Fagundes, 2015), de caráter qualitativo, apoiado na metodologia da pesquisa-ação com ênfase nos referenciais de Freire (1987) e Barbier (2007).

É importante destacar que, segundo a proposição de Barbier (2007), o rumo da metodologia pode mudar em razão das informações recebidas e de acontecimentos imprevisíveis, tendo em vista que a pesquisa-ação é uma opção metodológica que visa à ruptura de ciclos de repetição por meio da compreensão da realidade. Em relação à proposta de Freire (1987), esta se baseia na eliminação do método centrado na autoridade do educador que detém o saber e propõe uma educação conscientizadora, que parte da percepção do educando. Assim, as ações educativas realizadas permitem a reflexão, o conhecimento e a transformação da realidade mediante a interação do indivíduo em sua integralidade, além do desenvolvimento de habilidades que favorecem o conhecimento do corpo e os agravos à saúde em seu sentido mais amplo, segundo concepções pedagógicas que contemplem a liberdade e a cidadania. 


\section{O local}

O local escolhido foi a cidade de Vitória, capital do Espírito Santo. Com base no índice de qualidade urbana (IQU), composto por quatro dimensões (educacional, habitacional, ambiental e renda - quanto maior o IQU, melhor é a qualidade urbana), foram identificados os bairros menos desenvolvidos do município, e dentre estes se adotaram como critérios de seleção do bairro onde a pesquisa seria realizada: inserção prévia da Universidade Federal do Espírito Santo (Ufes) e grupo de gestantes constituído na unidade de saúde. Com base nesse critério, a UBS de Andorinhas foi eleita. Essa opção sustentou-se no referencial 'freireano', por se tratar de uma população que vive uma realidade oprimida por suas condições sociais (Freire, 1987), e no conceito de intencionalidade proposto por Thiollent (2009), segundo o qual os indivíduos são escolhidos em razão da relevância que apresentam para o estudo.

\section{Inserção no local de estudo}

Para a execução do projeto, tornou-se necessária a obtenção de autorização da Prefeitura de Vitória, por meio de avaliação da Escola Técnica de Formação Profissional (ETSUS). Posteriormente, a equipe de pesquisadores foi recepcionada pela diretora da unidade selecionada para o estudo e pela enfermeira responsável pelo grupo de gestantes. Nessa oportunidade, foram esclarecidos os objetivos da pesquisa.

Para a escolha dos participantes do estudo, definiram-se alguns critérios de seleção: gestantes em acompanhamento pré-natal na unidade de saúde; profissionais da saúde que tivessem contato com as gestantes durante o período pré-natal; aceitação em participar da pesquisa e assinatura do termo de consentimento livre e esclarecido. Essa etapa do estudo foi de fundamental importância para a obtenção de resultados positivos, pois, de acordo com Barbier (2007), é por meio dessa contratualização e desse conhecimento das intenções da pesquisa-ação que as contribuições de cada participante podem ser definidas.

Após a manifestação de interesse e autorização por parte da UBS, definiu-se que o momento inicial de abordagem dos possíveis participantes do estudo aconteceria nas reuniões das equipes um e dois, para abordagem do maior número de profissionais de saúde envolvidos no pré-natal, enquanto as gestantes seriam localizadas no arquivo da unidade e contatadas por telefone sobre a ocorrência da pesquisa, fazendo-se o agendamento 
de um encontro com aquelas que se interessassem em participar, para maiores esclarecimentos. Assim, após a apresentação da pesquisa, agendou-se um encontro com cada equipe de saúde e um com as gestantes, para se relacionarem os temas mais relevantes a serem trabalhados segundo a ótica da comunidade.

O projeto da pesquisa foi aprovado pelo Comitê de Ética em Pesquisa da Ufes, com o número 537.448-21/02/2014, atendendo aos requisitos da resolução n. 466/2012.

\section{Etapas para a construção do projeto de educação em saúde}

A pesquisa transcorreu no período de abril a dezembro de 2014 e contou com cinco etapas: inserção no local de estudo; levantamento temático (palavras e temas geradores); elaboração de proposta para a educação em saúde; oficinas de cultura (rodas de discussão e reflexão acerca dos temas levantados); e problematização e busca de soluções para os problemas relacionados ao longo do estudo. É importante destacar que essa divisão por etapas visou apenas tornar a apresentação da pesquisa mais didática; entretanto, na prática essas fases não foram tão bem delineadas, pois de acordo com a concepção teórica da pesquisa-ação há uma verdadeira reflexão-ação-reflexão, pelo fato de os participantes adquirirem uma consciência crítica ao longo do processo, o que muitas vezes torna necessário o retorno às questões iniciais ou permite o surgimento de novas indagações que levam à emancipação e ao empoderamento. Neste artigo, são apresentados os resultados das etapas um, dois e três e suas respectivas contribuições para o campo da educação em saúde no pré-natal.

\section{Levantamento de palavras e temas geradores}

Na primeira etapa proposta por Paulo Freire, realizou-se o levantamento das 'palavras e temas geradores' por meio da realização de três encontros dois com profissionais de saúde da unidade e um com as gestantes. Essa opção por dialogar com os atores em momentos distintos foi tomada para se evitar que algum participante no momento inicial se sentisse constrangido e também a fim de explicar, de maneira aprofundada, a lógica da pesquisa-ação e do pensamento dialógico proposto por Paulo Freire (1987).

O primeiro encontro foi realizado na reunião de equipe semanal que ocorria na UBS de Andorinhas juntamente com a equipe de saúde da família 1 . Contou com 12 participantes (dois enfermeiros, uma psicóloga, uma assistente social, três cirurgiões-dentistas, uma auxiliar de enfermagem, duas agentes comunitárias de saúde e dois alunos de iniciação científica que tam- 
bém atuaram como auxiliares de pesquisa) e durou uma hora e meia aproximadamente. O segundo encontro foi realizado 15 dias após a realização do primeiro, com a equipe de saúde da família dois, também na reunião de equipe semanal. Houve a participação de sete pessoas: dois médicos, dois dentistas, a pesquisadora e duas alunas de graduação (fonoaudiologia e odontologia) que atuaram também como auxiliares durante o encontro, que durou aproximadamente uma hora.

Nos dois encontros com profissionais, propôs-se uma conversa fundamentada em três eixos principais: histórico e metodologia das atividades de educação em saúde no pré-natal realizadas no local; formação específica para atuar com educação em saúde; principais desafios e ideias para a educação em saúde. Assim, foi possível que cada participante refletisse sobre a situação vivenciada e buscasse respostas para os desafios encontrados na prática.

O terceiro encontro foi realizado na sequência, com a participação de gestantes adstritas na UBS em acompanhamento pré-natal. A seleção prévia das mulheres realizou-se com base na Rede Bem-Estar, pertencente à Prefeitura de Vitória (sistema de informatização de prontuários), em que foram identificadas 24 gestantes em acompanhamento pré-natal na unidade. Seis gestantes tinham o contato telefônico de acordo com o cadastro e aceitaram participar da pesquisa. No dia do encontro houve a participação efetiva de quatro gestantes, uma enfermeira, uma aluna do curso de enfermagem, uma aluna de graduação da fonoaudiologia e dois cirurgiões-dentistas.

Nesse encontro, após os esclarecimentos iniciais, foi anexado um cartaz na parede com a questão: “o que a gestante deseja?”. Ofereceram-se jornais e revistas variados para que cada participante, inclusive a equipe de pesquisa, recortasse, de modo a anexar ao cartaz figuras que representassem aquilo que, na concepção de cada um, era uma necessidade da gestante para o pré-natal. Estabeleceu-se o tempo de trinta minutos para executar a atividade, após o qual cada um deveria explicar para o grupo o motivo pelo qual escolhera a figura que anexou ao cartaz, sendo que os outros poderiam complementar as ideias caso desejassem. Esse momento de troca de ideias e percepções entre os participantes possibilitou um reconhecimento sobre temas a serem trabalhados no processo de educação em saúde no pré-natal. Ao final, os temas eleitos para os próximos encontros foram colocados à disposição para que os participantes decidissem em qual ordem gostariam de trabalhar cada assunto. O grupo optou por definir o assunto central do encontro subsequente ao final de cada reunião. Essa decisão do grupo aproximou-se do cerne da pesquisa-ação, pois seu planejamento não deve ser rígido e necessita de flexibilidade para se adaptar às diversas situações impostas pela vida (Barbier, 2007). 


\section{Análise de dados}

Para a coleta dos dados da pesquisa, adotou-se a observação participante, com a elaboração de um diário de campo. Além disso, todos os encontros foram gravados em áudio e transcritos.

A análise dos dados foi realizada por meio de discussões e reflexões acerca do material obtido, inicialmente pela equipe responsável pela pesquisa, momento em que eram feitas aproximações com os referenciais teóricos utilizados no estudo. Em cada encontro subsequente as conclusões parciais eram apresentadas ao grupo de gestantes e profissionais de saúde, que novamente refletiam e elaboravam ideias e respostas acerca de cada assunto proposto, em conformidade com a proposição de Barbier (2007), segundo a qual a análise de dados da pesquisa-ação exige uma espiral de revisões para a ação e para o pensamento, questionando-se ininterruptamente o discurso estabelecido. Ao final desse processo, foi possível elaborar um relatório final com as teorias e comparações elaboradas pelo grupo que participou das atividades educativas.

Nesta pesquisa, utilizou-se o software de análise de dados qualitativos MAXqda 11.0 como auxílio na busca de palavras e temas, códigos, descodificação e desvelamentos presentes nas transcrições, pois de acordo com Gibbs (2009) as pesquisas qualitativas necessitam de um gerenciamento cuidadoso devido às grandes quantidades de textos, códigos e memorandos, trabalho que se torna ideal para o computador. Assim, os programas de análise de dados qualitativos, como o que foi utilizado, proporcionam uma forma poderosa e estruturada de administrar todos esses aspectos da análise.

\section{Codificações e descodificações: a compreensão do percurso}

No levantamento de palavras e temas geradores, identificaram-se 22 palavras geradoras. Essas palavras foram agrupadas em cinco temas gerais e resultaram na elaboração de cinco oficinas temáticas, nas quais se realizaram dinâmicas para estimular a reflexão acerca dos assuntos propostos, de modo que os temas codificados fossem descodificados, ou seja, que os participantes passassem a refletir criticamente sobre o objeto de análise por meio das discussões.

A Figura 1 apresenta a elaboração das etapas iniciais da pesquisa. Ao longo do estudo que deu origem a este artigo, buscou-se o desenvolvimento da consciência crítica de cada participante para uma compreensão mais aprofundada acerca da educação em saúde no pré-natal. Assim, a discussão apresentada a seguir foi estruturada nos três encontros iniciais conforme os eixos de problematização produzidos pelo participantes: superação da 
educação bancária para a conquista de uma educação ético-crítico-política; e reinvenção do conteúdo tradicional da educação em saúde no pré-natal. Na visão de Freire (2014), essa aproximação com a comunidade, os verdadeiros atores do processo educativo local, é de fundamental importância para que se saiba com quem contar e contra quem ou o que é preciso estar, para assim estabelecer o diálogo acerca da mudança difícil, necessária, mas não impossível.

É importante também destacar que cada palavra, cada tema, cada problematização se apresenta na figura interligada dentro de um círculo aberto, pois de acordo com Freire (1987), ao oferecerem possibilidades plurais de análises no processo de sua descodificação, as codificações funcionam como uma espécie de 'leque temático', em que o sujeito desconstrói o objeto de análise para reconstruí-lo com um novo olhar. Segundo essa concepção também se encontram os fundamentos da pesquisa-ação, que é pautada na ideia da reflexão-ação-reflexão (Barbier, 2007).

\section{Figura 1}

Itinerário da pesquisa-ação para a educação em saúde no pré-natal fundamentada no referencial de Paulo Freire

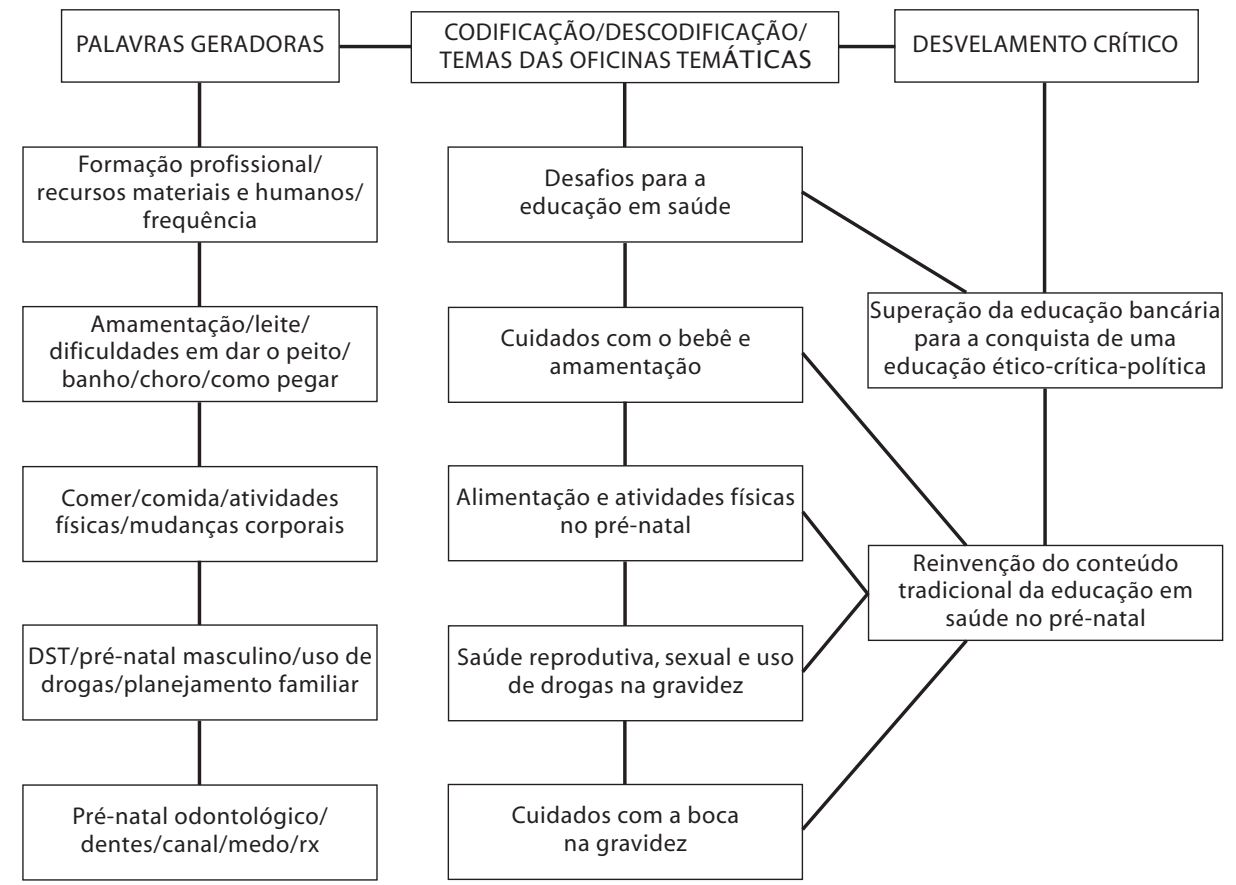

Fonte: Os autores.

Nota: DST - Doença sexualmente transmissível; $\mathrm{Rx}$ - raios $\mathrm{X}$. 


\section{Superação da educação bancária: a luta por uma educação ético-crítico-política}

Nos primeiros encontros com os profissionais, as primeiras palavras geradoras (educação em saúde/formação profissional/recursos materiais e humanos) emergiram nos discursos dos participantes quando estes foram indagados acerca do histórico de práticas educativas realizadas na comunidade, dos desafios encontrados e das condições materiais e humanas oferecidas para esse trabalho.

Quando os pesquisadores se aproximaram da história das atividades de educação já realizadas na UBS, foi possível compreender a visão predominantemente adotada na condução do processo educativo:

O último grupo de gestante que eu participei eram encontros semanais, e em cada encontro tinha um profissional para tá falando de um assunto diferente com a gestante, um dia um nutricionista, um dia o professor de educação física entre outros (Profissional de saúde 1).

Mas era um grupo assim que se convidassem doze, às vezes apareciam seis, às vezes a primeira até dá bastante gente, aí depois vai reduzindo, reduzindo. Isso me deixa, assim, sem estímulo como profissional (Profissional de saúde 2).

No contexto vivenciado pelos profissionais de saúde, é possível entender que a condução da educação em saúde sempre foi fundamentada no discurso ou 'palestra' que cada profissional deveria realizar, enquanto as gestantes, ou 'alunas', apenas 'ouviam' - situação que na visão dos responsáveis pelas atividades não se mostrava interessante, pois o imaginário popular é permeado pela visão curativa e biomédica da saúde centrada na figura do médico.

Eu acho que isso são paradigmas, porque a valorização da população é o que... é médico na hora, é remedinho na hora, o que fugir disso não é aceito (Profissional de saúde 2).

E às vezes vem numa palestra, tem que ouvir, tem que aprender a mudar os seus hábitos, e isso exige esforço, e não é bem assim que acontece (Profissional de saúde 3).

De acordo com Freire (1987), essa educação fundamentada no que o profissional fala é dita 'educação bancária', porque o educador deposita conhecimentos nos educandos, ou seja, só o educador fala, e os educandos devem se adaptar às prescrições impostas. Para Alves e Aerts (2011), mesmo tendo sido questionadas nos últimos anos, as práticas educativas ainda seguem um modelo autoritário, em que os trabalhadores da saúde continuam 
a fazer prescrições sobre o comportamento mais adequado e a população acata sem questionar ou relacionar esses conteúdos à sua realidade. Por isso, é fundamental que a filosofia dialógica seja apresentada a todas as classes profissionais da saúde, as quais em sua maioria vivenciaram uma educação verticalizada e apenas reproduzem aquilo que aprenderam em sua formação.

Na minha época tinha muito pouco essa abordagem (Profissional de saúde 4).

Dentro da saúde da família, que é onde poderia estar fazendo educação em saúde, eu tive, sim, na graduação, e era opcional, a gente não fazia nem prova (Profissional de saúde 5).

Tanto na formação quanto na residência, buscava-se já desde o princípio o foco que era o seu aprendizado voltado pra aquela área que você ia atuar, não tinha discussão, conversa, uma troca de saberes (Profissional de saúde 6).

A constatação unânime por parte dos profissionais participantes das rodas de discussões iniciais de que suas formações foram fundamentadas em um modelo curativo - e pouco voltado para o diálogo - foi percebida pelas gestantes, quando indagadas a respeito de como se sentiam em relação aos serviços de educação em saúde oferecidos na UBS.

Eu acho que educar as pessoas não gasta tanto tempo se for todo dia, só que isso não acontece (Gestante 2).

Aqui no posto eles não falam tudo porque aqui é só o básico, unidade básica mesmo, então eles não tem esse suporte todo de sentar com todo mundo (Gestante 4).

Aqui tem dois ginecologistas obstetras, mas infelizmente eles não tão aqui pra atender esse lado educativo. Eles só vão atender uma gestante se chegar aqui passando mal. Fazer um pré-natal, acompanhar a gestante, não tem (Gestante 3).

No estudo realizado por Oliveira e Wendhausen (2014) sobre a prática da educação em saúde pelos trabalhadores do SUS, identificou-se que a formação acadêmica recebida por estes é insuficiente para trabalhar com a comunidade. Para os autores, essa é a realidade enfrentada por quase todos que atuam na Estratégia Saúde da Família (ESF) e sem dúvida um obstáculo a ser superado. Acerca disso, Freire (1987) nos oferece elementos para a mudança do padrão educativo vigente, os quais permitem ao profissional que se propõe a ser também um educador o desenvolvimento da autenticidade por meio do pensar do educando, mediatizados pela realidade e pelo diálogo e não pela simples prescrição. 
O descompasso na educação em saúde, que resulta no despreparo dos trabalhadores, nem sempre vem do aporte teórico recebido, mas está aliado ao desestímulo advindo da falta de recursos humanos, materiais e da grande quantidade de atribuições impostas aos profissionais na atual realidade da ESF.

O tempo que o enfermeiro tá digitando lá o número de cartão SUS ele poderia tá dando palestra nas escolas (Profissional de saúde 2).

Tivemos uma formação pra desenvolver nosso trabalho, mas somos impedidos, pois não nos é oferecido recursos humanos e materiais (sic) (Profissional de saúde 7).

O recurso material faz muita diferença pra gente, e nós não temos nem pra comprar um balão pra encher e enfeitar a unidade (Profissional de saúde 1).

Essa situação também foi visualizada pelas usuárias dos serviços de saúde, que também expressaram o desconforto causado pelo grande volume de pacientes concentrados nas dependências da unidade em razão das metas de produtividade impostas pela administração do SUS:

Por que que eles marcam tudo assim agarradinho? Porque que vai tudo pra prefeitura. Cês acham que eles vão marcar uma hora pra cada um, sabendo que quem vai reclamar é a prefeitura? (Gestante 4).

No dia que eu fui fazer o teste da orelhinha, cheguei e tinha mais de 20 mulher ( sic) esperando tudo na mesma hora. Tava todo mundo brigando. Isso tudo porque é mandado lá pra aquele negócio da prefeitura (Gestante 2).

De acordo com Freire (1992), a situação atual do sistema de saúde brasileiro está intrincada com a política e com o jogo de poder entre os que dominam e os que são dominados, ou seja, a população que mais precisa de cuidados, pois quanto menos os sonhos forem cultivados, quanto menos os dominados exercitarem a aprendizagem política e se tornarem abertos aos discursos 'pragmáticos', mais serão controlados. Por isso é fundamental refletir e perguntar: por que num sistema pautado pela universalidade, integralidade e equidade é necessário se acostumar com o discurso do 'SUS para o pobre' e do 'não tem jeito'?

A falta de estrutura física e humana também foi visualizada por Oliveira e Wendhausen (2014), que destacam que, apesar de verdadeiro, tal problema pode ser discutido em um contexto que prioriza as atividades educativas e as discute com a população. Ou seja, no pensamento 'freireano' 
se identifica uma situação de dificuldade dita 'situação-limite', que se for transcendida leva ao chamado 'inédito viável', em que a ação real é pautada por um processo crítico-reflexivo que leva à mudança (Freire, 1987).

Ademais, Freire (1992) considera que a verdadeira função do educador é encontrar possibilidades. Paralelamente, Barbier (2007) destaca a importância de a pesquisa-ação submeter seus resultados à avaliação de todos os participantes que, em coletividade, determinam os meios para a resolução das dificuldades. Dessa maneira, a equipe de pesquisa e os participantes do estudo decidiram em conjunto discutir, ao longo dos encontros, de qual forma os problemas encontrados para a realização das atividades de educação em saúde poderiam ser contornados. Por meio da proposição de ideias, foi possível levantar possibilidades reais para a prática da educação em saúde dialógica por meio do planejamento interdisciplinar.

Acho que os profissionais devem se reunir, reservar um horário pra planejar esses assuntos (Profissional de saúde 8).

Planejar junto, né, assim todos os profissionais têm uma riqueza muito grande de conhecimento (Profissional de saúde 9).

A gente percebe que quando uma atividade é planejada com antecedência, nós temos mais êxito (Profissional de saúde 8).

Essa postura profissional demonstrou uma ideia horizontal nas relações entre profissionais do serviço público de saúde, a qual ainda não foi solidificada em todos os serviços, pois como apontado por Peduzzi (2000), na prática assistencial não acontecem a interação e a articulação de saberes e ações, o que dificulta a elaboração de um projeto pautado na integralidade. Diante desse panorama, Matos e Pires (2009) propõem a adoção de uma postura interdisciplinar para compreender melhor a multidimensionalidade do objeto de trabalho em saúde e para proporcionar melhores resultados no trabalho.

Em consonância, a PNEPS (Brasil, 2013) enfatiza que a construção do projeto democrático e popular é a reafirmação do compromisso com uma sociedade justa, solidária, democrática, igualitária, soberana e culturalmente diversa, que só será fortalecida por meio das lutas sociais e da garantia do direito universal à saúde no Brasil, tendo como protagonistas os sujeitos populares, que historicamente foram silenciados e marginalizados. Assim, entendemos que a educação em saúde como objeto de trabalho do SUS deve ser repensada mediante um planejamento integrado, de modo que não haja apenas transmissão de conhecimentos, mas que a equipe e a comunidade sejam capazes de construir um projeto rico e dinâmico. 


\section{Reinventar o conteúdo tradicional da educação em saúde no pré-natal}

"A experiência não pode ser exportada, ela só pode ser reinventada", diz Freire (2014, p. 27) em relação ao conteúdo e à forma do ensino, de modo que essa atividade não seja apenas a cópia de um método pronto. É preciso, então, que as pessoas estejam completamente envolvidas pela cultura e pelo espaço onde atuam para que democraticamente o caminho da educação seja trilhado.

Após conhecer a realidade e os dilemas enfrentados pelos profissionais de saúde participantes da pesquisa-ação, as gestantes da comunidade foram convidadas a participar, independentemente do estágio gestacional, para que pudéssemos apreender as visões das diferentes etapas percorridas pela mulher nesse período de sua vida. Logo, houve a elaboração de uma proposta educativa norteada por percepções não imaginadas pelos trabalhadores locais, o que confirmou a importância de todo projeto educativo ser submetido à discussão com seus participantes, pois do contrário o insucesso será previsível.

Quando se questionou o grupo de gestantes acerca de como elas pensavam que deveria ser o trabalho em um grupo de educação em saúde para o pré-natal, a primeira reflexão elaborada por algumas participantes foi sobre a falta de participação do homem durante o período pré-natal e sobre a necessidade de que a consciência masculina se tornasse reflexiva.

Acho que precisa de uma reunião com os pais, pra abrir a mente deles, porque tem cara que não se comporta como pai (Gestante 1).

Podia ter uma reunião pra eles ter o entendimento do que é uma gestação com a mulher (Gestante 2).

A identificação da necessidade do apoio masculino tornou-se mais intensa no decorrer do encontro e revelou, por meio de experiências e depoimentos, a existência de uma composição familiar ainda patriarcal, pois na maioria dos relatos a mulher era responsabilizada socialmente por todos os eventos relacionados à gravidez, enquanto o homem em muitos casos era visto apenas como o mantenedor financeiro do lar, não se envolvendo emocionalmente com o cuidado do bebê.

A mesma reflexão também foi feita pelos profissionais de saúde, no sentido da importância do estabelecimento de vínculo entre a ESF e o núcleo familiar como forma de melhorar os resultados do pré-natal.

Quando a gente consegue identificar o casal, e oferecer o pré-natal associado, você consegue trazer um suporte melhor, você consegue fazer com que o apoio do parceiro se torne um ponto de facilitação (Profissional de saúde 5). 
Esse parceiro, também teria que se ter um grupo pra ele, porque ele às vezes... os próprios parceiros se interessam mais (Profissional de saúde 7).

Esse tema não tem importância apenas local, mas vem sendo enfatizado atualmente por organismos como a Organização Mundial da Saúde (OMS), que discute uma atenção pré-natal centrada nas famílias e dirigida para as necessidades não só da mulher e de seu filho, mas também do casal (Brasil, 2005). Entretanto, Oliveira e colaboradores (2009) relatam em seu estudo que a inserção do homem no pré-natal por meio do convite não é uma prática cotidiana nos serviços de saúde, atitude evidenciada como necessária pelos participantes desta pesquisa, que ao longo de todos os encontros discutiram ideias futuras sobre como oferecer serviços na UBS adequados aos horários em que os homens pudessem estar presentes. E é nesse ponto que a concepção 'freireana' oferece o diferencial, ao possibilitar a problematização para a mudança, pois de acordo com Freire (1987) essa problematização é importante para a transformação permanente da realidade e para a permanente humanização de homens.

O segundo tema eleito para discussão pelo grupo foram a alimentação e as atividades físicas no período gestacional. Os métodos utilizados pela UBS para discutir esse tema foram criticados pelas participantes em suas falas.

Uma enfermeira daqui, que eu não vou citar o nome, ela falou bem assim pra mim: "Olha, você tem que comer tudo light... porque você não pode engordar". Eu achei errado mesmo (Gestante 2).

Às vezes não temos condições de ter a alimentação mesmo, às vezes por causa do tempo, às vezes porque é muito caro ter uma alimentação saudável também (Gestante 1).

Fui perguntar a minha médica o que que eu deveria comer, aí ela falou assim que eu deveria comer só comida integral, aí eu falei assim: “Lógico que não! Eu vou comer e vou comer o dobro ainda. Se eu engordar meu filho, eu não me importo" (Gestante 3).

Os questionamentos levantados pelas gestantes, na visão de Freire (2014), demonstraram que elas começavam a questionar a realidade imposta, ou seja, o saber médico científico imposto, e a se reconhecer como sujeitos para ter um diálogo empoderado acerca de sua saúde com os 'doutores'. Nessa perspectiva, em vez de ditar normas, é preciso que os profissionais de saúde problematizem os temas, de modo a valorizar a autonomia, a cultura e a realidade de cada indivíduo, gestante ou não. Ainda de acordo com Freire (2014), a atividade de questionar é sempre fascinante, e as questões sempre levam a outras. É por meio de temas aparentemente universais para qual- 
quer grupo de educação em saúde de gestantes que se torna possível que estas não se adaptem a fórmulas definidas, mas que assumam a responsabilidade de 'ser' no mundo.

Em relação ao tema amamentação, todas as gestantes participantes relataram dificuldades e a necessidade de aprender por meio de cursos e debates sobre como amamentar. Além disso, criticaram o fato de não receberem esse conhecimento dos profissionais de saúde envolvidos no pré-natal.

Uma vez eu fui pedir uma ajuda, no entanto a mulher não me ajudou; aí eu ficava desesperada porque eu não sabia dar ele [dar o peito ao bebê], daí graças a Deus apareceu uma médica boa que me ensinou como dar, mas só foi aquele dia lá; eu dei poucas vezes porque eu não conseguia dar, não sabia como dar (Gestante 4).

Eu fui ficando muito nervosa, peguei a bombinha, fui dando da chuquinha uns bons dias... mas daí meu peito foi crescendo muito, foi empedrando, eu fui parar lá na clínica pra tirar o leite na maternidade... aí, daí não consegui dar (Gestante 3).

É importante destacar, contudo, que durante a preparação prévia para o desenvolvimento do encontro a própria equipe de pesquisa teve dúvidas quanto ao interesse das mulheres em discutir a amamentação, por ser um dos temas mais comentados em grupos de gestantes. Da mesma forma, no encontro inicial com os profissionais da unidade de saúde do local estudado, ao serem questionados sobre possíveis temas a serem trabalhados com mulheres grávidas, o ato de amamentar não foi citado. Por isso, ficou evidente que as percepções acadêmicas e do ambiente de trabalho do SUS para a população muitas vezes não são adequadas em razão do pouco diálogo entre esses atores, e fazem-se urgente a mudança de conduta e a adoção de práticas pautadas na humanização e na concepção 'freireana'.

A simples transmissão de conteúdos sobre como amamentar não supre as necessidades das mulheres, de acordo com Freire (2014), qualquer assunto que vá ser ensinado necessita examinar a existência humana em seus conhecimentos, suas estruturas, inter-relações, representações e práticas, a fim de que o tema central, a leitura do mundo e a maneira de conhecer o mundo permitam a tomada de consciência que leve à transformação. Assim, é fundamental que os profissionais de saúde considerem o universo local e a realidade vivenciada de cada gestante participante.

Além dos temas já destacados, as gestantes trouxeram à luz discussões acerca dos cuidados bucais da gestante e do bebê e dos cuidados após o parto. A saúde bucal também foi assunto eleito pelos profissionais da saúde, mesmo sendo ainda pouco enfatizado no âmbito do SUS. Também permaneceram grandes mitos em relação a esse tema, como é possível identificar nas falas dos atores. 
Ele ia ter que usar muita anestesia, e eu fiquei assim, pode prejudicar meu filho, porque se eles já falaram assim, se você não escovar os dentes direito, vai passar para o seu filho, imagine anestesia (Gestante 4).

Então, faz parte do pré-natal, é obrigatório, só que algumas preferem ir na consulta só do médico e não ir na odontologia (Profissional de saúde 7).

Existem barreiras a serem vencidas, a resistência a fazer o pré-natal odontológico, fazer um tratamento odontológico, preconceitos, no caso aí pela cultura (Profissional de saúde 8).

Outros estudos apontam as deficiências em relação ao atendimento odontológico no período gestacional, atribuindo a baixa procura por esses serviços a crenças que decorrem da associação entre gestação e odontologia (Konishi e Lima, 2002; Codato, Nakama e Melchior, 2008). Essa condição é definida por Freire (2011) como uma consciência mágica da realidade, que carece de um processo educativo pautado pela conscientização, pois “o homem é consciente, na medida em que conhece, e tende a se comprometer com a própria realidade" (Freire, 2011, p. 50).

Para reinventar a educação em saúde, segundo Vasconcelos (2004) é preciso compreender que um 'programa' de educação não se faz 'para' o povo, mas 'com' o povo, e toma como ponto de partida do processo pedagógico o saber desenvolvido no trabalho, na vida social e na luta pela sobrevivência, procurando incorporar os modos de sentir, pensar e agir dos grupos e das camadas exploradas e oprimidas para ajudá-los em sua luta. Assim, a visão 'freireana' rompe a hegemonia do saber do educador ao criar uma condição horizontal entre educadores e educandos, na medida em que eles passam a se educar num processo criador e humanizador, como foi possível atestar nas falas avaliativas das gestantes acerca da execução desta pesquisa.

Eu gostei porque a gente participou, não foi só aquele negócio de datashow que a gente só escuta, ninguém fala nada, não dá opinião de nada. Aqui a gente interagiu com todo mundo, falamos um pouquinho de cada coisa que a gente pensa e mais pra frente eu tenho certeza que a gente vai dialogar mais porque em cada etapa vai ser um tema diferente (Gestante 1).

Eu gostei porque eu não fazia ideia nenhuma das coisas do pré-natal mesmo; deu pra abrir a minha mente porque teve uma conversa (Gestante 4). 


\section{Considerações finais}

Por meio da execução da pesquisa apresentada neste artigo, foi possível perceber que a construção de uma proposta de educação em saúde para o pré-natal pautada na proposta da pesquisa-ação e em Paulo Freire permitiu que as sugestões dos profissionais de saúde e das gestantes se complementassem, tendo em que vista que cada sujeito apresentou suas dificuldades, refletiu e dialogou na busca por um consenso.

Para a ampliação e a execução dessa proposta em outras comunidades e UBSs dentro do SUS, diante das dificuldades reveladas pelo estudo, deve-se ter o apoio programático e compromissado para uma educação em saúde transformadora nos moldes de Paulo Freire. Portanto, é essencial que novos estudos sejam realizados com os gestores e administradores do serviço de saúde do país, para que se compreendam outras faces do problema e sejam encontradas soluções que beneficiem todos os cidadãos brasileiros.

É preciso destacar algumas limitações do estudo aqui apresentado, uma vez que, embora a proposta educativa tenha sido elaborada e desenvolvida pelo grupo formado, a continuidade desse tipo de trabalho estava atrelada ao interesse da administração dos serviços de saúde em oferecer as condições necessárias para a elaboração e a prática da educação em saúde problematizadora. Além disso, para que se torne possível aumentar as possibilidades de construção de um projeto de educação em saúde democrático, a gestão do SUS deveria também ser envolvida no processo de pesquisa-ação, pois de acordo com Freire (1979), somente avançando em direção a um horizonte utópico, mas possível, é que a realidade deixa de se apresentar como um beco sem saída e toma o seu verdadeiro aspecto: um desafio a que os homens devem responder.

\section{Colaboradores}

Daniely Quintão Fagundes e Adauto Emmerich Oliveira atuaram igualmente na elaboração de todas as etapas do artigo e declaram não haver conflito de interesses. 
Resumen En este artículo, se discutió el proceso de construcción de una propuesta de educación en salud para el prenatal por parte de gestantes y profesionales de la salud, en base al referencial teórico de Paulo Freire. Se realizó un estudio cualitativo apoyado en la metodología de investigación-acción en una unidad básica de salud del municipio de Vitória, capital del estado de Espírito Santo, Brasil, en 2014. Los datos se recolectaron por medio de la observación participante, con la grabación en audio de los encuentros. El análisis del material ocurrió simultáneamente, y en cada reunión los resultados parciales eran sometidos a la evaluación de los participantes, que nuevamente discutían y reflexionaban sobre las conclusiones obtenidas. Esas evaluaciones permitieron preparar un informe final del proceso con la propuesta de acciones de transformación de la realidad. Los resultados mostraron que profesionales de la salud y gestantes contribuían en forma diferenciada y complementaria en la selección de temas para la educación en el prenatal, poniendo de manifiesto la importancia de las interacciones entre funcionarios e usuarios en las construcciones de proyectos educativos fundamentados en el diálogo. También se destacaron problemas organizacionales y estructurales en los servicios de salud que dificultaban la realización de las actividades, haciendo necesarias reflexiones-acciones que involucren gestores y administradores del Sistema Único de Salud, a fin de que la educación se vuelva una prioridad. Palabras clave educación en salud; cuidado prenatal; investigación cualitativa.

\section{Notas}

1 Universidade Federal Fluminense, Niterói, Rio de Janeiro, Brasil.

$<$ danielyqfagundes@hotmail.com>

Correspondência: Avenida Marquês de Paraná, 191, Centro, CEP 24030-215, Niterói, Rio de Janeiro, Brasil.

2 Universidade Federal do Espírito Santo, Centro Biomédico, Departamento de Medicina Social, Vitória, Espírito Santo, Brasil.

$<$ adautoemmerich@terra.com.br> 


\section{Referências}

ALVES, Gehysa G.; AERTS, Denise. As práticas educativas em saúde e a Estratégia Saúde da Família. Ciência \& Saúde Coletiva, Rio de Janeiro, v. 16, n. 1, p. 319-325, jan. 2011.

BARBIER, René. A pesquisa-ação. Brasília: Líber Livro, 2007.

BRASIL. Ministério da Saúde. Manual técnico de pré-natal e puerpério: atenção qualificada e humanizada. Brasília: Ministério da Saúde, 2005. Disponível em : <http://bvsms. saude.gov.br/bvs/publicacoes/pre-natal_ puerperio_atencao_humanizada.pdf $>$. Acesso em: 16 jan. 2015.

BRASIL. Portaria n. 2.761, de 19 de novembro de 2013. Institui a Política Nacional de Educação Popular em Saúde no âmbito do Sistema Único de Saúde (PNEPS-SUS). Diário Oficial da União, Brasília, DF, 20 nov 2013. Disponível em: <http://bvsms.saude. gov.br/bvs/saudelegis/gm/2013/prt2761_ 19_11_2013.html>. Acesso em: 21 jan. 2015.

CODATO, Lucimar A. B.; NAKAMA, Luiza; MELCHIOR, Regina. Percepções de gestantes sobre atenção odontológica durante a gravidez. Ciência \& Saúde Coletiva, Rio de Janeiro, v. 13, n. 3, p. 1.075-1.080, jun. 2008.

FAGUNDES, Daniely. Ações construtivas de educação em saúde para o pré-natal. $160 \mathrm{f}$. Dissertação (Mestrado em Saúde Coletiva) Centro de Ciências da Saúde, Universidade Federal do Espírito Santo, Vitória, 2015.

FREIRE, Paulo. Conscientização: teoria e prática da libertação - uma introdução ao pensamento de Paulo Freire. São Paulo: Cortez \& Moraes, 1979.

FREIRE, Paulo. Pedagogia do oprimido. 17. ed. Rio de Janeiro: Paz e Terra, 1987.

FREIRE, Paulo. Pedagogia da esperança: um reencontro com a pedagogia do oprimido. 4. ed. Rio de Janeiro: Paz e Terra, 1992.
FREIRE, Paulo. Educação em mudança. 2. ed. São Paulo: Paz e Terra, 2011.

FREIRE, Paulo. Pedagogia da solidariedade. São Paulo: Paz e Terra, 2014.

GIBBS, Graham. Análise de dados qualitativos. Porto Alegre: Artmed, 2009.

KONISHI, Flávia; LIMA, Fábio A. Odontologia intrauterina: a construção da saúde bucal antes do nascimento. Revista Brasileira de Odontologia, Rio de Janeiro, v. 59, n. 5, p. 294-295, set.-out. 2002.

MARTINELLI, Katrini G. et al. Adequação do processo da assistência pré-natal segundo os critérios do Programa de Humanização do Pré-Natal e Nascimento e Rede Cegonha. Revista Brasileira de Ginecologia e Obstetrícia, Rio de Janeiro, v. 36, n. 2, p. 56-64, fev. 2014.

MATOS, Eliane; PIRES, Denise E. P. Práticas de cuidado na perspectiva interdisciplinar: um caminho promissor. Texto \& Contexto Enfermagem, Florianópolis, v. 18, n. 2, p. 338-346, jun. 2009.

MORIN, André. Pesquisa-ação integral e sistêmica: uma antropopedagogia renovada. Rio de Janeiro: DP\&A, 2004.

OLIVEIRA, Lucia C. et al. Participação popular nas ações de educação em saúde: desafios para os profissionais da atenção primária. Interface: Comunicação, Saúde, Educação, Botucatu, v. 18, supl. 2, p. 1.389-1.400, dez. 2014.

OLIVEIRA, Sheila C. et al. A participação do homem/pai no acompanhamento da assistência pré-natal. Cogitare Enfermagem, Curitiba, v. 14, n. 1, p. 73-8, jan. 2009.

OLIVEIRA, Silvia R. G.; WENDHAUSEN, Águeda L. P. (Re)significando a educação em saúde: dificuldades e possibilidades da Estratégia Saúde da Família. Trabalho, Educação e Saúde, Rio de Janeiro, v. 12, n. 1, p. 129-147, abr. 2014. 
PAIM, Jairnilson S. Reforma sanitária brasileira: contribuição para a compreensão e crítica. Rio de Janeiro: Editora Fiocruz, 2008.

PEDUZZI, Marina. Equipe multiprofissional de saúde: a interface entre trabalho e interação. Resenha. Interface: Comunicação, Saúde, Educação, Botucatu, v. 4, n. 6, p. 151, fev. 2000 .

RIOS, Claudia T. F.; VIEIRA, Neiva F. C. Ações educativas no pré-natal: reflexão sobre a consulta de enfermagem como um espaço para educação em saúde. Ciência \& Saúde Coletiva, Rio de Janeiro, v. 12, n. 2, p. 477-486, abr. 2007.

SANTOS NETO, Edson T. et al. Acesso à assistência odontológica no acompanhamento pré-natal. Ciência \& Saúde Coletiva, Rio de Janeiro, v. 17, n. 11, p. 3057-3068, nov. 2012.

SARTORI, Graziele S.; VAN DER SAND, Isabel C. P. Grupo de gestantes: espaço de conhecimentos, de trocas e de vínculos entre os participantes. Revista Eletrônica de Enfermagem, Goiânia, v. 6, n. 2, p. 153-165, 2004. Disponível em: <http://revistas.ufg. br/fen/article/view/821/949>. Acesso em: 15 jan. 2015.

SERRUYA, Suzanne J.; CECATTI, José G.; LAGO, Tania G. O Programa de Humanização no Pré-Natal e Nascimento do Ministério da Saúde no Brasil: resultados iniciais. Cadernos de Saúde Pública, Rio de Janeiro, v. 20, n. 5, p. 1.281-1.289, out. 2004.
SOUZA, Viviane B.; ROECKER, Simone; MARCON, Sônia S. Ações educativas durante a assistência pré-natal: percepção de gestantes atendidas na rede básica de Maringá-PR. Revista Eletrônica de Enfermagem, Goiânia, v. 13, n. 2, p. 199-210, jun. 2011. Disponível em: <www.revistas.ufg.br/fen/article/ view/10162/9621>. Acesso em: 8 jan. 2015.

THIOLLENT, Michel. Metodologia da pesquisa-ação. 17. ed. São Paulo: Cortez, 2009.

TRINDADE, Wânia R.; FERREIRA, Márcia A. Sexualidade feminina: questões do cotidiano das mulheres. Texto \& Contexto Enfermagem, Florianópolis, v. 17, n. 3, p. 417-426, set. 2008.

VASCONCELOS, Eymard M. Educação Popular: de uma prática alternativa a uma estratégia de gestão participativa das políticas de saúde. Physis: Revista de Saúde Coletiva, Rio de Janeiro, v. 14, n. 1, p. 67-83, 2004. Disponível em: <www.scielo.br/pdf/physis/ v14nl/v14nla05.pdf $>$. Acesso em: 2 jan. 2015.

Recebido em 06/02/2015

Aprovado em 31/05/2016 